\title{
Pathogenicity and cytological examination of adapted and non- adapted Bipolaris species on resistant and susceptible cultivars of rice and corn
}

\section{Amorio DJH and Cumagun CJR*}

Crop Protection Cluster, College of Agriculture, University of the Philippines Los Baños, College, Laguna 4031 Philippines, Email: christian_cumagun@yahoo.com

Amorio DJH, Cumagun CJR 2017 - Pathogenicity and cytological examination of adapted and non-adapted Bipolaris species on resistant and susceptible cultivars of rice and corn. Mycosphere 8(3) 377-391, Doi 10.5943/mycosphere/8/3/3

\begin{abstract}
The genus Bipolaris causes two important cereal diseases: brown spot of rice (Bipolaris oryzae) and leaf spot of corn (Bipolaris maydis). This study examined the morphology of the two Bipolaris species and its pathogenicity and cytology on resistant and susceptible rice and corn cultivars. Resistant (CH-45) and susceptible (IR-72) rice cultivars were inoculated with $B$. oryzae (adapted) and B. maydis (non-adapted) isolates. B. oryzae was pathogenic on both rice cultivars producing higher lesion density and size on the susceptible cultivar at 3 to 5 days after inoculation which is significantly different from the resistant cultivar $(\mathrm{P}=0.05)$. B. maydis was non-pathogenic on both rice cultivars. Resistant (Sweet Grande) and susceptible (SuperSweet) corn cultivars were also inoculated with two Bipolaris spp. B. maydis was pathogenic on both corn cultivars producing higher lesion density and size on the susceptible cultivar at 7 days after inoculation which is significantly different from the resistant cultivar $(\mathrm{P}=0.05)$. B. oryzae was non-pathogenic on both corn cultivars. At the cytological level, conidia of both Bipolaris species germinated on two hosts but only $B$. maydis produced appressoria on resistant and susceptible corn cultivars. $\mathrm{H}_{2} \mathrm{O}_{2}$ accumualtion around the hyphal tips is due to the turgor pressure exerted by the hyphae which forces the DAB stain to acumulate in the immediate surrounding of the swollen hyphae at $24 \mathrm{~h}$ after inocualtion. In contrast, death cells, also a form of defense response were formed around the attempted penetration site on resistant rice cultivar inoculated with $B$. maydis at $24 \mathrm{~h}$ after inoculation. This study suggests that in rice-corn cropping system, $B$. oryzae is not a potential source of inoculum for leaf spot of corn. Likewise, B. maydis is not a potential source of inoculum for brown spot of rice.
\end{abstract}

Key words - brown spot of rice - host range - leaf spot of corn

\section{Introduction}

Brown spot of rice (BS) caused by Bipolaris oryzae Breda de Haan (teleomorph: Cochliobolus miyabeanus Ito and Kuribayashi) is a destructive disease of rice which under favorable conditions causes severe reductions (Strange 2003). In the Philippines, brown spot is still 
considered as a minor disease but its incidence has been repeatedly observed in many rice growing areas of the country. Ocfemia (1924) reported 10-58\% seedling mortality in the country as the disease causes seedling blight from heavily infected seed. Typical symptoms of the disease include spots on the leaves which are brown and oval, about the size of a sesame seed and evenly distributed over the leaf surface. When fully developed, spots appeared with grey or whitish centers and often surrounded with yellow-brown halo. On susceptible varieties, the leaf withers as spots are larger and more numerous ( $\mathrm{Ou}$ 1985). The disease was implicated as a major contributor to the Bengal famine of 1942 during which an estimate of 2 million people died, the losses then amounting to 50-90\% (Padmanabhan 1973, Chakrabarti 2001). On the other hand, leaf spot of corn caused by Bipolaris maydis Shoemaker (teleomorph: Cochliobolus heterostrophus Drechsler) is a common disease affecting corn plantation in many tropical and subtropical areas of the world (Drechsler 1925, Orillo 1952, Yu 1933, Kronstad 2000). Typical tan and elongated lesions begin on lower leaves and progress up the plant. The most notable symptoms are found on corn containing Texas-male sterile cytoplasm (T-cytoplasm) with lesions up to several centimeters in length surrounded by a dark red to purple border. Lesions are observed on the leaves, ear husks, kernels and stalks where ears rotted inside husks and stalks fell to the ground (Partridge 1997). The disease was first reported in the Philippines as early as 1961 when corn with T-cytoplasm increased its susceptibility to certain isolates of $C$. heterostrophus although its occurrence is not seriously considered until the epidemic in 1970 (Mercado\&Lantican 1961, Kronstad 2000). This disease made a historical significance in the American agriculture because of its epidemics that destroyed $15 \%$ of the United States maize crop (Callahan 2010).

Although brown spot of rice and leaf spot of corn have brought significant and damaging effects on rice and corn respectively, planting of corn after rice in the rainfed and upland areas of the country is being practiced primarily to reduce pest and raise farm incomes (Adriano 1989). In the mid-1970's, International Rice Research Institute (IRRI) initiated rice-based cropping studies which led to the introduction of crops other than rice during the dry season following the wet season rice crop. This form of cropping system is now being promoted in the Aurora region in the Philippines to prevent soil depletion and maintain soil fertility according to the Philippine Rice Research Institute (PhilRice) (Anon 2014). However, the impact of carry-over of the inoculum in a rice-corn cropping system has not been properly documented given that the causal pathogen of brown spot of rice and leaf spot of corn has the same genera Bipolaris (teleomorph: Cochliobolus). Understanding how plants defend themselves from pathogens is essential in order to protect the food supply and increase crop production. Hence, the purpose of this study is to determine whether $B$. oryzae serves as potential source of inoculum for leaf spot of corn or B. maydis as potential source for brown spot of rice.

\section{Materials \& methods}

\section{Isolation and preservation of fungal cultures}

Leaf samples showing symptoms of leaf spot of corn were collected around University of the Philippines Los Baños (UPLB) campus. The collected leaf samples were brought to the laboratory for the isolation of pathogens associated with them. Lesions on the leaves caused by leaf spot of corn were swabbed by moist cotton to remove any waxy material on the surface. Whole lesions with a part of healthy tissues were cut out and submerged in $10 \%$ sodium hypochlorite solution with a drop of Tween 80 for 1-2 minutes to disinfect the tissues. Tissue sections were rinsed on sterile distilled water twice and blotted with paper towel to remove excess hypochlorite solution. Four to five sections were placed in the initially prepared Potato Dextrose Agar (PDA) plates using sterile forceps under the clean bench. Plates were wrapped using parafilm and incubated at room temperature for 3-5 d. Pure cultures were prepared by sub-culturing from the isolation plates and incubating the cultures for 7-10 days to obtain sufficient growth. B. oryzae 
isolate was requested from IRRI, Los Baños, Laguna. The isolate was then transferred to PDA slants to obtain stock cultures. Pure culture of the two fungal pathogens (B. maydis and B. oryzae) were maintained on PDA slants and stored for further use.

\section{Pathogenicity test}

Resistant (CH-45) and susceptible (IR-72) rice varieties were planted in clay pots and replicated three times per time period. Each pot contains at most five rice seeds. The same set-up was done in corn plants using Sweet Grande resistant and Super Sweet susceptible varieties. Urea was applied at a rate of one gram per pot prior to sowing of rice and corn. All cultural and pest management practices were done to ensure that the plants are in good condition prior to inoculation. Twenty-one day old seedlings of corn (at 3- 4 leaf stages) and one-month old rice plant were used for inoculation. On the other hand, pure cultures of both B. maydis and B. oryzae were grown on V8-juice agar and subjected under alternating UV light (12 h) and dark (12 h) set-up for faster sporulation. Spore suspension was prepared from 7-14 day old pure culture of the isolates by scraping off the fungal growth using a sterilized wireloop. Sterile distilled water was poured into the slants before dislodging the spores on the surface of the tubes. Afterwards, suspension of both isolates were passed through four layers of cheesecloth to remove mycelial fragments and added with 2-3 drops of Tween 20 for the adhesion of spores to the leaves. Spore concentration was standardized at $1.4 \times 10^{4}$ conidia $\mathrm{ml}^{-}$using the haemocytometer following Tuite's procedure (Tuite 1969 ) before spraying to resistant and susceptible cultivars of rice and corn using an atomizer. The inoculum was sprayed on the marked aerial parts particularly on the second young fully expanded leaves for both rice and corn plants late in the afternoon. For control, plants were sprayed with sterile water alone. Inoculated plants were covered with moistened transparent bag for 24 hours. The plants were maintained inside the greenhouse until observation time. Inoculated rice and corn plants of adapted and non-adapted Bipolaris species were observed for the development of disease symptoms for one week. Disease severity was evaluated 3, 5 and 7 days after inoculation using the formula proposed by Sharma (2011). There were ten randomly leaf spots measured for lesion length and lesion density were counted on nine inoculated leaves. Lesion length and number were recorded and analyzed using the SAS program.

Percentage disease severity was computed using the formula proposed by Sharma (2011).

$\%$ Disease Severity $=\frac{\text { Sum of all disease rating }}{\text { Maximum disease grade } \mathrm{x} \text { Total number of plants rated }} \times 100$

\section{Microscopy and cytological analyses}

Pure cultures of the pathogen were grown under the agar-well set-up to visualize intact fruiting structures and minimize minimal disruption of the conidium-conidiophore relationship. Plates were incubated under alternating light $(12 \mathrm{~h})$ and dark $(12 \mathrm{~h})$ set-up for the sporulation of the pathogen for one week. Coverslips with the growth of the pathogen were placed on the slide, stained with cotton blue and visualized under the light microscope. Measurements and pictures were taken using an objective camera (Dinoscope) provided in the laboratory.

Inoculation with Bipolaris spp. was done at three weeks after planting of corn and one month after planting of rice using $1.4 \times 10^{4}$ conidia $\mathrm{ml}^{-}$inoculum using an atomizer. Rice and corn plants were inoculated at the same time. The inoculated plants were covered with moistened transparent plastic bag and incubated inside the greenhouse until observation time. Control plants were prayed with sterile water alone. Afterwards, leaves were harvested using a razor blade at 24, 3648,60 and 72 hours after inoculation on the marked area of the leaf. Leaf samples inoculated with adapted and non-adapted Bipolaris species were subjected to the following cytological tests: 
Microscopy observation of fungal structures. For assessment of epidermal host cell responses to attack; 10-15 leaf samples of each cultivar were fixed for light microscopy at five time periods. For fixation, $0.5 \mathrm{~cm}^{2}$ segment cut from marked area of the leaf were placed in a fixingclearing solution (70:30 ethanol-acetic acid) for at least $24 \mathrm{~h}$. After fixing and clearing, the sample tissues were transferred to $0.1 \%$ acid fuchsin in lacto phenol for 3 min to stain fungal structures; rinsed briefly for $10 \mathrm{~s}$ in plain lacto phenol to remove excess stain. Samples were then mounted in $50 \%$ glycerine in microscopic slides. Cover slips were gently applied and samples were viewed under the microscope. Number of germinated conidia and appressoria were examined on specific sites of leaf sample.

In-vivo detection of hydrogen peroxide and trypan blue staining. $0.5 \mathrm{~cm}^{2}$ of inoculated leaf was excised from the marked portion of the plant and placed in already prepared DAB solution $(\mathrm{pH}$ 3.0). Leaves were incubated in the growth chamber for another 8 hour period and fixed in a mixture of ethanol and acetic acid (96:4 v/v) overnight. DAB-stained leaves were observed under the microscope and visualized as a reddish-brown colouration (Thordal- Christensen et al. 1997). Trypan blue staining by Keogh et al. (1980) was followed with minor modification. Inoculated leaves were mounted and incubated in lactophenol with trypan blue $(10 \mathrm{ml}$ of lactic acid, $10 \mathrm{ml}$ of glycerol, $10 \mathrm{~g}$ of phenol and $10 \mathrm{mg}$ of trypan blue dissolved in $10 \mathrm{ml}$ of distilled water). Leaves were boiled in the solution for 1 minute and decolorized overnight in chloral hydrate solution $(75 \mathrm{~g}$ of chloral hydrate dissolved in $30 \mathrm{ml}$ distilled water).To detect cell death of both epidermal and mesophyll cells, stained leaves were incubated in chloral hydrate solution for $2 \mathrm{~h}$ (defined as low stringency washing). The inoculated leaves were observed by light microscopy. Death cells are stained blue while live cells are unstained.

\section{Data analysis}

The analysis of variance (ANOVA) for a two-way factorial design was used to analyze the main effects of species and variety on the pathogenic variation among Bipolaris species in rice and corn plants. Data on lesion length, lesion size and disease rating scale were analyzed using SAS analysis for Tukey's Studentisized Range (HSD).

\section{Results}

\section{Comparison of morphological characters of $B$. oryzae and $B$. maydis}

The purpose of this work is differentiate the morphology of the two Bipolaris species and determine its pathogenicity and cytology on resistant and susceptible rice and corn cultivars. The morphological description of B. oryzae and B. maydis is shown in Table 1.

Table 1 Morphological characteristics of Bipolaris spp. observed under 400X objective.

\begin{tabular}{lll}
\hline Character & Bipolaris oryzae & Bipolaris maydis \\
\hline Hilum & Papillate & Rounded to pointed \\
Conidia & Curved to Straight & Slightly curved \\
Conidiophore & Flexuous, solitary & Flexuous to straight, solitary \\
Length of conidia $(\mu \mathrm{m})$ & $35.00-170.00$ & $70-160$ \\
Width of condia $(\mu \mathrm{m})$ & $11.00-17.00$ & $15-20$ \\
Distoseptate & $6-13$ & $7-11$ \\
\hline
\end{tabular}




\section{Pathogenicity test of adapted and non-adapted Bipolaris spp. on susceptible and resistant cultivars of rice and corn}

For the pathogenicity test, symptom development of adapted and non-adapted Bipolaris spp. was assessed on resistant and susceptible cultivars of rice and corn at 3, 5 and 7 days after inoculation. Lesion size, lesion density and percentage disease severity were also taken for the test.

\section{A. Symptom development on resistant and susceptible cultivars of rice and corn}

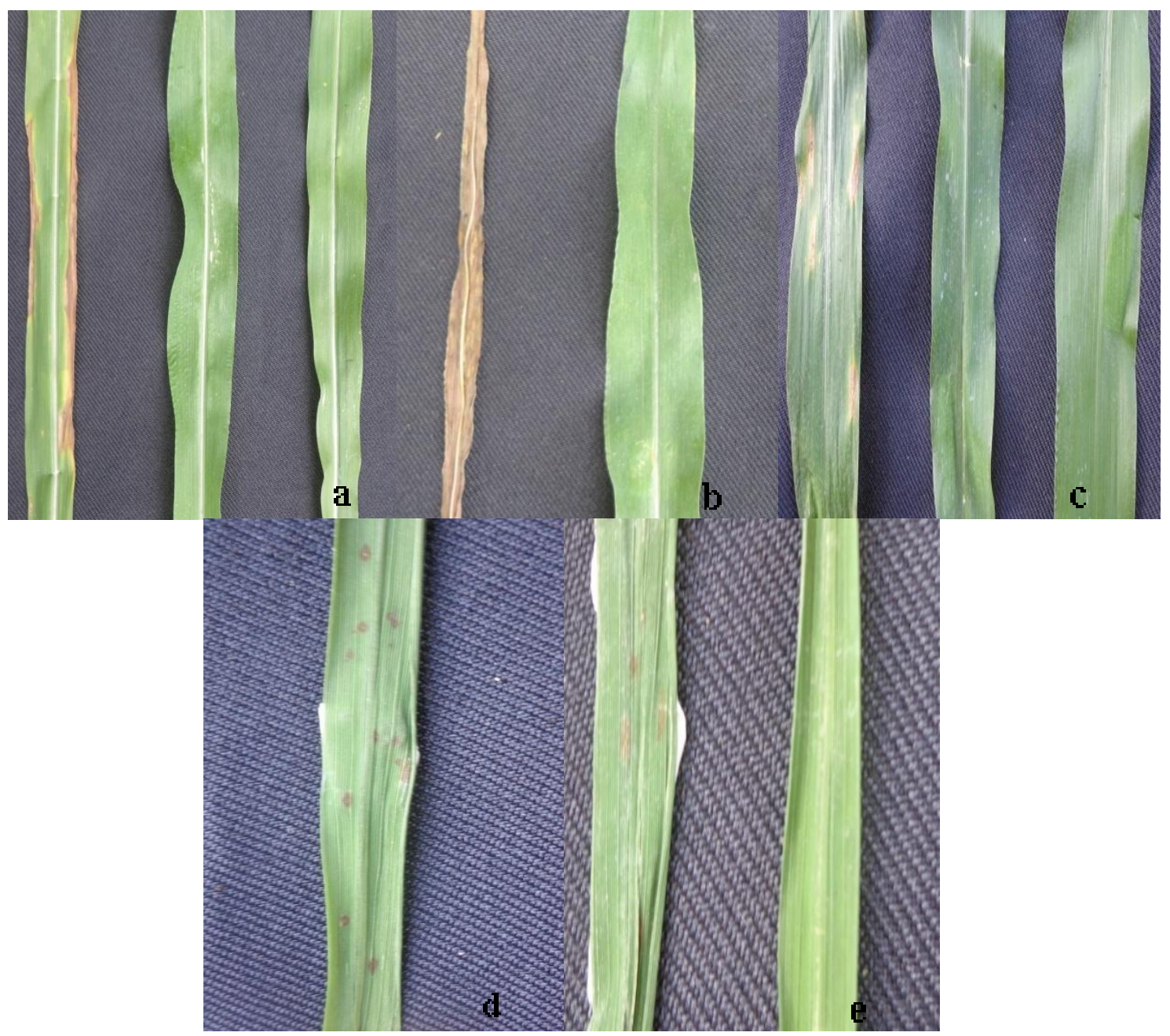

Fig. 1 -Symptom development in corn and rice leaves $7 \mathrm{~d}$ after inoculation. (a) susceptible corn variety inoculated with $B$. maydis (left), B. oryzae (center) and control (right), (b) susceptible corn variety inoculated with $B$. maydis (left) and $B$. oryzae (right), (c) resistant corn variety inoculated with $B$. maydis (left), B. oryzae (center) and control (right), (d) typical brown spot symptom on susceptible rice variety and (e) susceptible rice variety inoculated with $B$. oryzae (left) and $B$. maydis (right)

Leaves of susceptible corn cultivar inoculated with B. maydis (Fig. 1a) produced coalesced lesions with yellow halo at the margin of the leaf $7 \mathrm{~d}$ after inoculation. The symptom was absent on the same age leaves inoculated with B. oryzae (Fig. 1a, center) similar to the control treatment (Fig. 1a, right). The symptom was more pronounced on another susceptible corn cultivar as the leaf 
wilted and turned brownish in color due to the coalescing of numerous leaf spots on the surface (Fig. 1b). Resistant corn cultivar inoculated with B. maydis produced some longitudinal leaf spots (Fig. 1c, left) while no symptoms were observed on leaves inoculated with B. oryzae (Fig. 1c, center). Non-adapted Bipolaris species on rice leaves was non-pathogenic on both susceptible and resistant cultivar while typical brown spots developed on susceptible rice cultivar inoculated with B. oryzae (Fig. 1d).

B. Lesion density, lesion size and percentage disease severity of adapted and non-adapted Bipolaris species on resistant and susceptible rice cultivars

Table 2 Mean lesion density on rice leaves at 3rd, 5th and 7th day after pathogen inoculation with adapted and non-adapted Bipolaris species.

\begin{tabular}{|c|c|c|c|c|c|c|}
\hline \multirow{3}{*}{ Treatments } & \multicolumn{6}{|c|}{ Mean Lesion Density ${ }^{1}$} \\
\hline & \multicolumn{2}{|r|}{$3^{\text {rd }}$} & \multicolumn{2}{|c|}{$5^{\text {th }}$} & \multicolumn{2}{|l|}{$7^{\text {th }}$} \\
\hline & Bo & $\mathrm{Bm}$ & Bo & $\mathrm{Bm}$ & Bo & $\mathrm{Bm}$ \\
\hline $\begin{array}{l}\text { Resistant } \\
(\mathrm{CH}-45)\end{array}$ & $0.22^{\mathrm{b}}$ & $0.00^{\mathrm{b}}$ & $1.44^{\mathrm{b}}$ & $0.00^{\mathrm{b}}$ & $2.89^{\mathrm{ns}}$ & $0.00^{\mathrm{ns}}$ \\
\hline $\begin{array}{l}\text { Susceptible } \\
\text { (IR-72) }\end{array}$ & $4.22^{\mathrm{a}}$ & $0.00^{\mathrm{b}}$ & $5.33^{\mathrm{a}}$ & $0.00^{\mathrm{b}}$ & $9.11^{\mathrm{ns}}$ & $0.00^{\mathrm{ns}}$ \\
\hline Control & $0.00^{\mathrm{b}}$ & $0.00^{\mathrm{b}}$ & $0.00^{\mathrm{b}}$ & $0.00^{\mathrm{b}}$ & $0.00^{\mathrm{ns}}$ & $0.00^{\mathrm{ns}}$ \\
\hline
\end{tabular}

${ }^{1}$ Average of the number counted on nine, $2^{\text {nd }}$ to the youngest fully expanded leaves

Means with the same letters are not significantly different using Tukey's Studentisized Range (HSD) Test at $5 \%$ level of significance.

$\mathrm{Bm}=$ Bipolaris maydis, $\mathrm{Bo}=$ Bipolaris oryzae, $\mathrm{ns}=$ not significant

Susceptible rice cultivar inoculated with the adapted pathogen (B. oryzae) produced the highest mean number of brown spot lesions at $7 \mathrm{~d}$ after inoculation and was significantly different from the control and non-adapted pathogen (B. maydis) inoculated leaves across time points (Table $2)$. On the other hand, resistant rice cultivar inoculated with $B$. oryzae was not significantly different from the control and $B$. maydis inoculated leaves across same time points $(\mathrm{P}=0.05)$. Susceptible and resistant rice cultivar inoculated with B. maydis showed no production of lesions even after $5 \mathrm{~d}$ (Table 2).

Across time points, mean lesion size of susceptible rice cultivar inoculated with $B$. oryzae was significantly different compared to other treatments while resistant rice cultivar inoculated with the same pathogen doesn't differ from other treatments $(\mathrm{P}=0.05)$ (Table 3). Mean lesion size on susceptible cultivar inoculated with the adapted pathogen progresses while lesion size on resistant cultivar inoculated with the same pathogen remains the same across time points. Both varieties when inoculated with $B$. maydis produced no lesions similar to the control treatment (Table 3 ).

Percentage disease severity was highest on susceptible cultivar inoculated with $B$. oryzae and was significantly different among treatments across time points $(\mathrm{P}=0.05)$ (Table 4). The data follows the observed effect on lesion size and density which was also highest on susceptible rice cultivar inoculated with the same pathogen. Compared to resistant cultivar, the adapted isolate $B$. oryzae appeared more virulent when inoculated to susceptible one. It can be observed that when two varieties were inoculated with the non-adapted pathogen (B. maydis), there were no symptoms produced leading to $0 \%$ disease rating scale (Table 4 ) 
Table 3 Mean lesion size on rice leaves at 3rd, 5th and 7th day after pathogen inoculation with adapted and non-adapted Bipolaris species.

\begin{tabular}{|c|c|c|c|c|c|c|}
\hline \multirow[t]{3}{*}{ Treatments } & \multicolumn{6}{|c|}{$\begin{array}{c}\text { Mean Lesion Size } \\
(\mathrm{mm})\end{array}$} \\
\hline & \multicolumn{2}{|c|}{$3^{\mathrm{rd}}$} & \multicolumn{2}{|c|}{$5^{\text {th }}$} & \multicolumn{2}{|c|}{$7^{\text {th }}$} \\
\hline & Bo & $\mathrm{Bm}$ & Bo & $\mathrm{Bm}$ & Bo & $\mathrm{Bm}$ \\
\hline $\begin{array}{l}\text { Resistant } \\
(\mathrm{CH}-45)\end{array}$ & $0.10^{\mathrm{b}}$ & $0.00^{\mathrm{b}}$ & $0.10^{\mathrm{b}}$ & $0.00^{\mathrm{b}}$ & $0.10^{\mathrm{b}}$ & $0.00^{\mathrm{b}}$ \\
\hline $\begin{array}{l}\text { Susceptible } \\
\quad(\text { IR-72) }\end{array}$ & $1.54^{\mathrm{a}}$ & $0.00^{\mathrm{b}}$ & $1.48^{\mathrm{a}}$ & $0.00^{\mathrm{b}}$ & $1.81^{\mathrm{a}}$ & $0.00^{\mathrm{b}}$ \\
\hline Control & $0.00^{\mathrm{b}}$ & $0.00^{\mathrm{b}}$ & $0.00^{\mathrm{b}}$ & $0.00^{\mathrm{b}}$ & $0.00^{\mathrm{b}}$ & $0.00^{\mathrm{b}}$ \\
\hline
\end{tabular}

\footnotetext{
${ }^{1}$ Average of three replications

Means with the same letters are not significantly different using Tukey's Studentisized Range (HSD) Test at $5 \%$ level of significance.

$\mathrm{Bm}=$ Bipolaris maydis, $\mathrm{Bo}=$ Bipolaris oryzae, $\mathrm{ns}=$ not significant
}

Table 4 Percentage disease severity on rice leaves at 3rd, 5th and 7th day after pathogen inoculation with adapted and non-adapted Bipolaris species.

\begin{tabular}{|c|c|c|c|c|c|c|}
\hline \multirow{3}{*}{ Treatments } & \multicolumn{6}{|c|}{$\begin{array}{c}\text { Disease Severity }^{1} \\
(\%)\end{array}$} \\
\hline & \multicolumn{2}{|c|}{$3^{\text {rd }}$} & \multicolumn{2}{|c|}{$5^{\text {th }}$} & \multicolumn{2}{|c|}{$7^{\text {th }}$} \\
\hline & Bo & $\mathrm{Bm}$ & Bo & $\mathrm{Bm}$ & Bo & $\mathrm{Bm}$ \\
\hline $\begin{array}{l}\text { Resistant } \\
(\mathrm{CH}-45)\end{array}$ & $2.45^{\mathrm{b}}$ & $0.00^{\mathrm{b}}$ & $7.41^{\mathrm{c}}$ & $0.00^{\mathrm{c}}$ & $9.88^{\mathrm{b}}$ & $0.00^{\mathrm{c}}$ \\
\hline $\begin{array}{l}\text { Susceptible } \\
\quad \text { (IR-72) }\end{array}$ & $12.34^{\mathrm{a}}$ & $0.00^{\mathrm{b}}$ & $23.46^{\mathrm{a}}$ & $0.00^{b}$ & $25.93^{\mathrm{a}}$ & $0.00^{\mathrm{c}}$ \\
\hline Control & $0.00^{\mathrm{b}}$ & $0.00^{\mathrm{b}}$ & $0.00^{\mathrm{c}}$ & $0.00^{c}$ & $0.00^{\mathrm{c}}$ & $0.00^{\mathrm{c}}$ \\
\hline
\end{tabular}

${ }^{1}$ Computed using the formula proposed by Sharma (2011), average of three replications

Means with the same letters are not significantly different using Tukey's Studentisized Range (HSD) Test at 5\% level of significance.

$\mathrm{Bm}=$ Bipolaris maydis, $\mathrm{Bo}=$ Bipolaris oryzae, $\mathrm{ns}=$ not significant

C. Lesion density, lesion size and percentage disease severity of adapted and non-adapted Bipolaris species on resistant and susceptible corn cultivars 
Susceptible corn cultivar, Super Sweet, when inoculated with the adapted pathogen (B. maydis) showed the highest number of lesions $7 \mathrm{~d}$ after inoculation and was significantly different from other treatments $(\mathrm{P}=0.05)$ (Table 5). Similar results were also observed on rice leaves (Table 2) after which the susceptible cultivar inoculated with the adapted pathogen also showed the highest number of lesions. Similarly, both resistant and susceptible corn varieties when inoculated with the non-adapted pathogen (B. oryzae) were symptomless similar to the control across time periods.

Table 5 Mean lesion density on corn leaves at 3rd, 5th and 7th day after pathogen inoculation with adapted and non-adapted Bipolaris species.

\begin{tabular}{|c|c|c|c|c|c|c|}
\hline \multirow[t]{3}{*}{ Treatments } & \multicolumn{6}{|c|}{ Mean Lesion Density ${ }^{1}$} \\
\hline & \multicolumn{2}{|r|}{$3^{\text {rd }}$} & \multicolumn{2}{|c|}{$5^{\text {th }}$} & \multicolumn{2}{|l|}{$7^{\text {th }}$} \\
\hline & Bo & $\mathrm{Bm}$ & Bo & $\mathrm{Bm}$ & Bo & $\mathrm{Bm}$ \\
\hline $\begin{array}{c}\text { Resistant } \\
\text { (Sweet Grande) }\end{array}$ & $0.00^{\mathrm{ns}}$ & $15^{\mathrm{ns}}$ & $0.00^{\mathrm{b}}$ & $25.00^{\mathrm{a}}$ & $0.00^{\mathrm{c}}$ & $20.87^{\mathrm{b}}$ \\
\hline $\begin{array}{l}\text { Susceptible } \\
\text { (Super Sweet) }\end{array}$ & $0.00^{\mathrm{ns}}$ & $10.44^{\mathrm{ns}}$ & $0.00^{\mathrm{b}}$ & $10.00^{\mathrm{b}}$ & $0.00^{\mathrm{c}}$ & $40.00^{\mathrm{a}}$ \\
\hline Control & $0.00^{\mathrm{ns}}$ & $0.00^{\mathrm{ns}}$ & $0.00^{\mathrm{b}}$ & $0.00^{\mathrm{b}}$ & $0.00^{\mathrm{c}}$ & $0.00^{\mathrm{c}}$ \\
\hline
\end{tabular}

${ }^{1}$ Average of the number counted on nine, $2^{\text {nd }}$ to the youngest fully expanded leaves

Means with the same letters are not significantly different using Tukey's Studentisized Range (HSD) Test at $5 \%$ level of significance.

$\mathrm{Bm}=$ Bipolaris maydis, $\mathrm{Bo}=$ Bipolaris oryzae, $\mathrm{ns}=$ not significant

Table 6 Mean lesion size on corn leaves at 3rd, 5th and 7th day after pathogen inoculation with adapted and non-adapted Bipolaris species.

\begin{tabular}{|c|c|c|c|c|c|c|}
\hline \multirow[t]{3}{*}{ Treatments } & \multicolumn{6}{|c|}{$\begin{array}{c}\text { Mean Lesion Size } \\
(\mathbf{m m})\end{array}$} \\
\hline & \multicolumn{2}{|r|}{$3^{\text {rd }}$} & \multicolumn{2}{|c|}{$5^{\text {th }}$} & \multicolumn{2}{|l|}{$7^{\text {th }}$} \\
\hline & Bo & $\mathrm{Bm}$ & Bo & $\mathrm{Bm}$ & Bo & $\mathrm{Bm}$ \\
\hline $\begin{array}{c}\text { Resistant } \\
\text { (Sweet Grande) }\end{array}$ & $0.00^{\text {ns }}$ & $2.69^{\mathrm{ns}}$ & $0.00^{\mathrm{ns}}$ & $4.56^{\mathrm{ns}}$ & $0.00^{c}$ & $8.07^{\mathrm{b}}$ \\
\hline $\begin{array}{l}\text { Susceptible } \\
\text { (SuperSweet) }\end{array}$ & $0.00^{\mathrm{ns}}$ & $2.94^{\mathrm{ns}}$ & $0.00^{\mathrm{ns}}$ & $9.16^{\mathrm{ns}}$ & $0.00^{\mathrm{c}}$ & $13.85^{\mathrm{a}}$ \\
\hline Control & $0.00^{\mathrm{ns}}$ & $0.00^{\mathrm{ns}}$ & $0.00^{\mathrm{ns}}$ & $0.00^{\mathrm{ns}}$ & $0.00^{\mathrm{c}}$ & $0.00^{\mathrm{c}}$ \\
\hline
\end{tabular}

\footnotetext{
${ }^{1}$ Average of three replications

Means with the same letters are not significantly different using Tukey's Studentisized Range (HSD) Test at $5 \%$ level of significance.

$\mathrm{Bm}=$ Bipolaris maydis, $\mathrm{Bo}=$ Bipolaris oryzae, $\mathrm{ns}=$ not significant
} 
Mean lesion size obtained on resistant and susceptible varieties inoculated with B. maydis progresses across time periods with the largest mean lesion size on susceptible cultivar inoculated with the same pathogen (Table 6). Similar results were observed on rice leaves after inoculation of the adapted pathogen (Table 3). At 7d after inoculation, it can be observed that lesion size produced on susceptible cultivar inoculated with $B$. maydis was significantly different from other treatments $(\mathrm{P}=0.05)$ similar to resistant cultivar inoculated with the same pathogen (Table 6). Both varieties when inoculated with non-adapted pathogen (B. oryzae) were symptomless similar to control across time periods.

Table 7 Percentage disease severity on corn leaves at 3rd, 5th and 7th day after pathogen inoculation with adapted and non-adapted Bipolaris species.

\begin{tabular}{|c|c|c|c|c|c|c|}
\hline \multirow[t]{3}{*}{ Treatments } & \multicolumn{6}{|c|}{$\begin{array}{c}\text { Disease Severity }{ }^{1} \\
(\%)\end{array}$} \\
\hline & \multicolumn{2}{|c|}{$3^{\mathrm{rd}}$} & \multicolumn{2}{|c|}{$5^{\text {th }}$} & \multicolumn{2}{|c|}{$7^{\text {th }}$} \\
\hline & Bo & $\mathrm{Bm}$ & Bo & $\mathrm{Bm}$ & Bo & $\mathrm{Bm}$ \\
\hline $\begin{array}{c}\text { Resistant } \\
\text { (Sweet Grande) }\end{array}$ & $0.00^{\mathrm{ns}}$ & $26.67^{\mathrm{ns}}$ & $0.00^{\mathrm{ns}}$ & $30.98^{\mathrm{ns}}$ & $0.00^{\mathrm{c}}$ & $56.00^{\mathrm{b}}$ \\
\hline $\begin{array}{c}\text { Susceptible } \\
\text { (SuperSweet) }\end{array}$ & $0.00^{\mathrm{n}_{\mathrm{s}}}$ & $26.67^{\mathrm{ns}}$ & $0.00^{\mathrm{ns}}$ & $44.44^{\mathrm{ns}}$ & $0.00^{\mathrm{c}}$ & $91.11^{\mathrm{a}}$ \\
\hline Control & $0.00^{\mathrm{ns}}$ & $0.00^{\mathrm{ns}}$ & $0.00^{\mathrm{ns}}$ & $0.00^{\mathrm{ns}}$ & $0.00^{\mathrm{c}}$ & $0.00^{c}$ \\
\hline
\end{tabular}

${ }^{1}$ Computed using the formula proposed by Sharma (2011), average of three replications

Means with the same letters are not significantly different using Tukey's Studentisized Range (HSD) Test at 5\% level of significance.

$\mathrm{Bm}=$ Bipolaris maydis, $\mathrm{Bo}=$ Bipolaris oryzae, $\mathrm{ns}=$ not significant

Susceptible and resistant corn varieties when inoculated with the adapted pathogen, $B$. maydis produced lesions that progresses across time points. At $7 \mathrm{~d}$ after inoculation, susceptible cultivar inoculated with the adapted pathogen produced the highest percentage disease severity $(91.11 \%)$ and was significantly different among treatments (Table 7). Although resistant, B. maydis was able to produce symptoms on Sweet Grande resistant cultivar with 56\% disease rating scale. Similar to the results of rice when inoculated with non-adapted pathogen (Table 4), both corn varieties were symptomless $(0 \%$ disease severity) when inoculated with non-adapted B. oryzae similar to control treatment across time points.

\section{Microscopic observation of fungal structures on rice and corn leaves}

Number of germinated conidia and appressoria were counted on the specific sites of the leaves at 24, 36, 48, 60 and $72 \mathrm{~h}$ after inoculation. The number generated per time period were combined and summarized in Tables 8 and 9. 
Table 8 Germinated conidia and appressoria counted per $0.5 \mathrm{~cm}^{2}$ of corn leaf across time points.

\begin{tabular}{ccc}
\hline \hline \multirow{2}{*}{ Treatments } & \multicolumn{2}{c}{ Number of Fungal Structures Counted Across Time Points } \\
\cline { 2 - 3 } & Germinated Conidia & Appressoria \\
\hline *SC+Bm & 18 & 4 \\
SC+Bo & 6 & 0 \\
RC + Bm & 16 & 7 \\
RC+Bo & 7 & 0 \\
\hline \hline
\end{tabular}

*i.e. Susceptible corn inoculated with $B$. maydis

$\mathrm{SC}=$ Susceptible Corn, $\mathrm{RC}=$ Resistant Corn

$\mathrm{Bm}=$ Bipolaris maydis, $\mathrm{Bo}=$ Bipolaris oryzae

Under the light microscope, susceptible corn section of the leaf inoculated with B. maydis (adapted pathogen) was observed to have the highest number of germinated conidia followed by resistant corn inoculated with the same pathogen. In addition, the adapted pathogen was able to produce an appressorium after its germination. On the other hand, non-adapted pathogen ( $B$. oryzae) inoculated on resistant and susceptible corn varieties was able to germinate however, fail to produce an appressorium. It can be observed that the number of germinated conidia to its host surface was higher compared to its germination to non-host surface. In addition, conidia inoculated on host surface were able to produce an appressorium, a fungal structure not observed on non-host surface.

Fig. 2 below shows the microscopic conidial germination and appressorium formation of $B$. maydis on susceptible and resistant corn cultivar. The pathogen inoculated on susceptible corn cultivar, germinated in a bipolar manner within 24 to $36 \mathrm{~h}$ after inoculation (Fig 2a and 2b) and formed distinct appressoria after $48 \mathrm{~h}$ of inoculation (Fig 2c). On the other hand, B. oryzae inoculated in a resistant corn cultivar germinated in a bipolar manner with no appressorium formation at $48 \mathrm{~h}$ after inoculation.

Table 9 Germinated conidia and appressoria counted per $0.5 \mathrm{~cm}^{2}$ of rice leaf across time points.

\begin{tabular}{llll}
\multirow{2}{*}{ Treatments } & \multicolumn{3}{c}{ Number of Fungal Structures Counted Across Time Points } \\
\cline { 2 - 4 } & \multicolumn{3}{c}{ Germinated Conidia } \\
\hline SR+ Bm & 7 & 0 & Appressoria \\
SR+Bo & 6 & 0 & \\
RR + Bm & 2 & 0 & \\
RR+Bo & $2 *$ & 0 & \\
\hline
\end{tabular}

* Most of the observed condia were ungerminated

$\mathrm{SR}=$ Susceptible Rice, $\mathrm{RR}=$ Resistant Rice

$\mathrm{Bm}=$ Bipolaris maydis, $\mathrm{Bo}=$ Bipolaris oryzae

Conidia of both Bipolaris spp. germinated on susceptible and resistant rice varieties. Susceptible rice cultivar inoculated with $B$. oryzae produced the highest number of germinated conidia compared to resistant one wherein most of the conida observed were ungerminated. This was reflected in the pathogenicity test observed in Fig 1 wherein susceptible rice cultivar when inoculated with the adapted pathogen produced significant lesion size and lesion density compared to other treatments. The higher the number of germinating conidia, the higher the probability to 
cause infection on leaf. Unlike the microscopic observation of fungal structures of Bipolaris spp on corn leaf, formation of appressoria on rice leaf were not observed among treatments even on its host plant.

\section{Cytological staining of fungal strucutres using Diaminobenzidine tetrahydrochloride (DAB) and Trypan Blue (TB)}

Cellular defense response of rice and corn plants were observed using various staining techniques. 3,3- diaminobenzidine (DAB) polymerizes instantly and locally as soon as it comes to contact with $\mathrm{H}_{2} \mathrm{O}_{2}$ into a reddish brown polymer in the presence of peroxidase. Fig 3 below shows the formation of reddish brown polymer around the swollen hyphal strand (abnormal diameter) caused by the adapted $B$. maydis pathogen.

In the case of the hyphal elongation observed, adapted B.maydis forces its ways inside of cells causing the hyphal tips to swell (Fig 3b-B, Figc 3d-D). The accumulation of $\mathrm{H}_{2} \mathrm{O}_{2}$ around the hyphal tips is due to the turgor pressure exerted by the hyphae which forces the DAB stain to accumulate in the immediate surrounding of the swollen hyphae. It has been proposed that a rapid increase in either intra-or extracellular $\mathrm{H}_{2} \mathrm{O}_{2}$ is involved in the induction and/or execution of the hypersensitive response(HR).
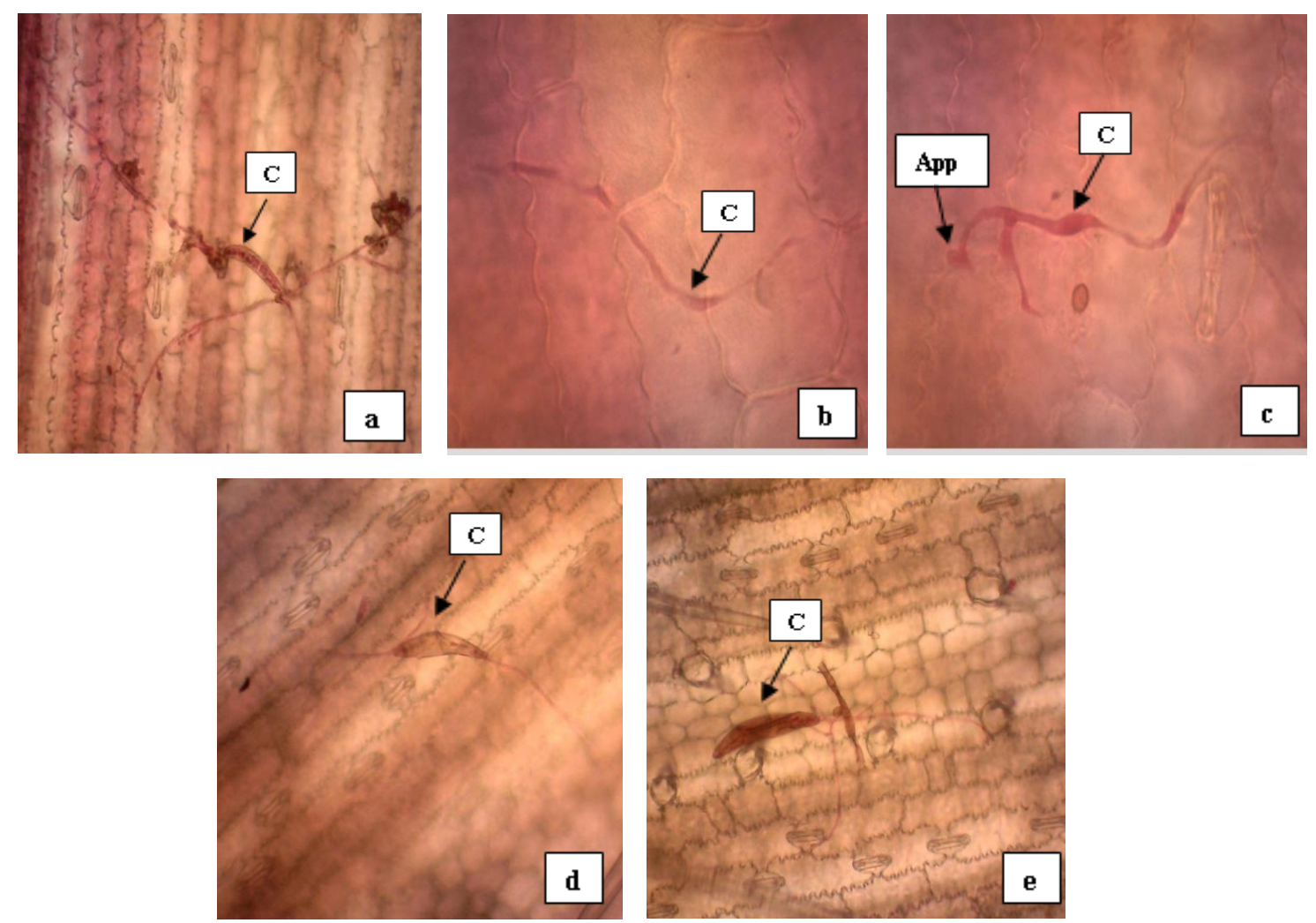

Fig 2- Light microscopic observation of fungal structures at $0.5 \mathrm{~cm}^{2}$ of corn leaf observed under $400 X$ objective. (a) and (b) bipolar germination of the conidia (C) of B. maydis inoculated on susceptible corn variety at 24 and $36 \mathrm{~h}$ after inoculation, (c) formation of appresorium (App) of $B$. maydis at $48 \mathrm{~h}$ after inoculation, (d) and (e) germination of B.oryzae on resistant corn variety. Cconidia, App- appressorium 

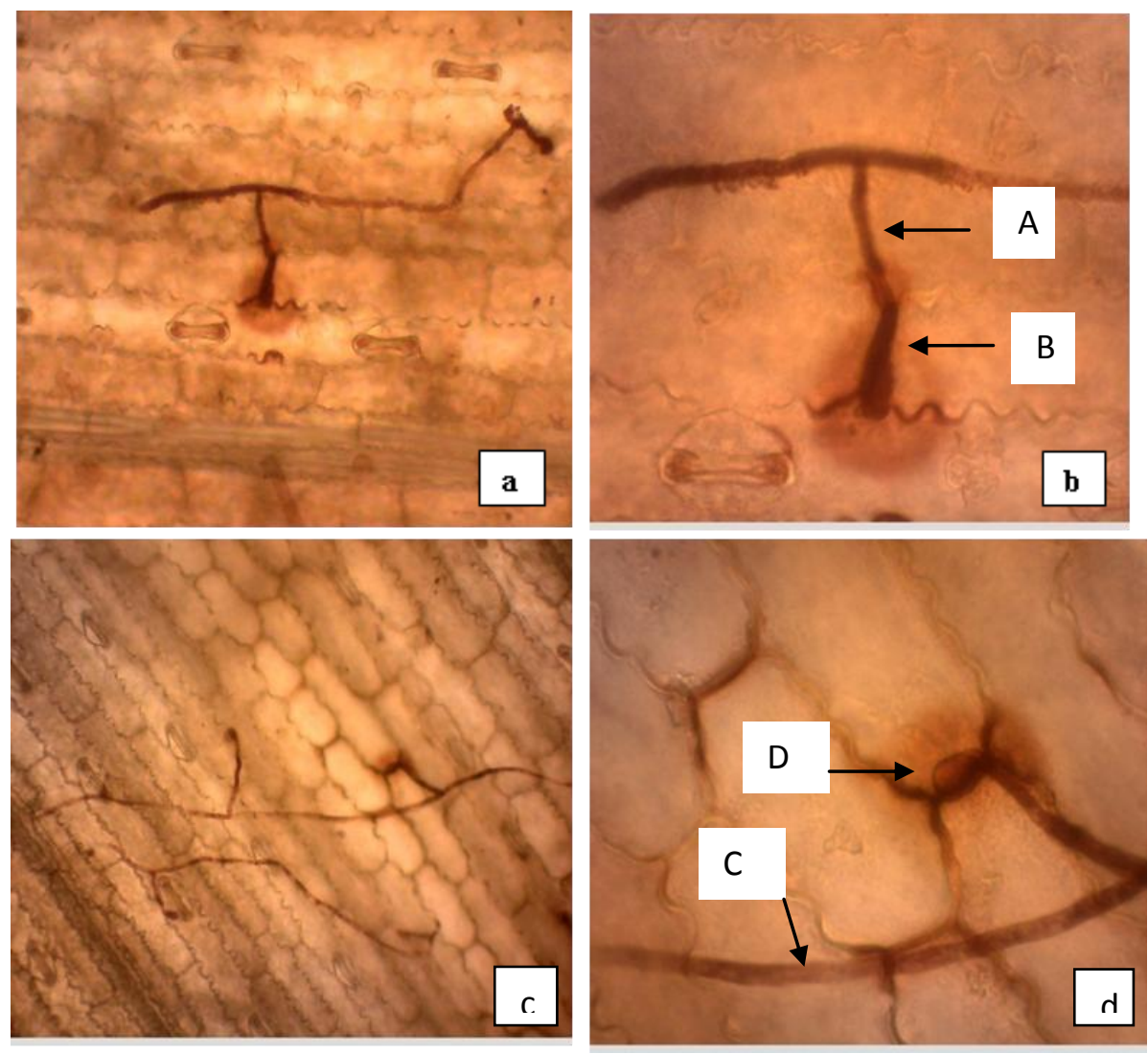

Fig 3- $\mathrm{H}_{2} \mathrm{O}_{2}$ accumulation in the epidermal cells of susceptible corn inoculated with B. maydis at 24 $\mathrm{h}$ after inoculation. (a) and (c) hyphal branching observed at 400X objective, (b) normal diameter of hyphal strand (A) compared to swollen hyphae (B) at 1000X objective (B), (d) another normal elongation of hyphal strand (C) compared to swollen hyphae (D) at 1000X objective.

\section{Detection of death cells by trypan blue staining}

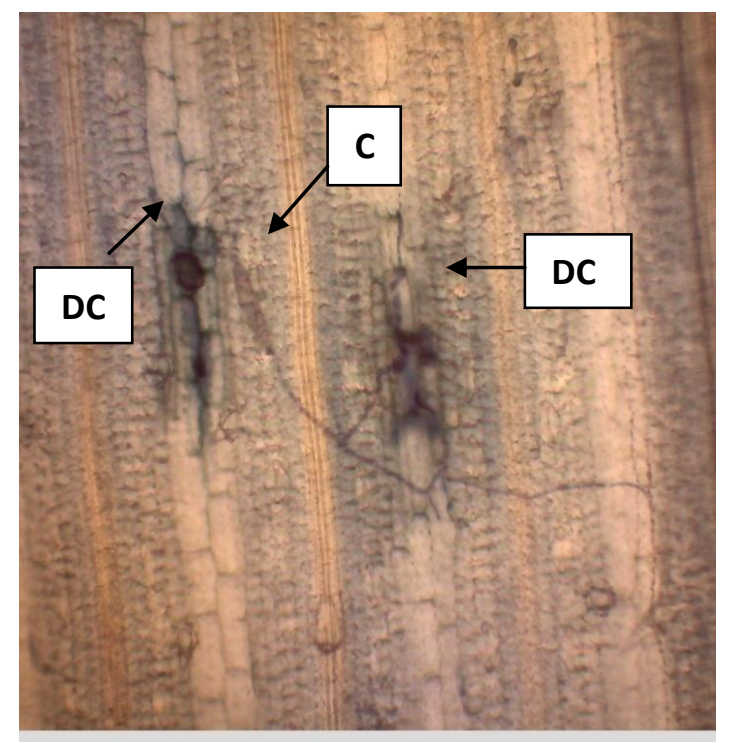

Fig 4- Resistant rice leaf inoculated with non-adapted B. maydis stained with trypan blue $24 \mathrm{~h}$ after inoculation. Dead cells (DC) are stained blue around the germinating conidia (C). 
Resistant rice cultivar inoculated with the non-adapted pathogen when stained under trypan solution produced blue coloration of the nearby cells around the attempted penetration site (Fig 4). Trypan blue is a solution that indicates formation of dead cells which is a defense response of the plant called "hypersensitive response (HR).

\section{Discussion}

The study examined the morphology of the two Bipolaris species and its pathogenicity and cytology on resistant and susceptible rice and corn cultivars. Pathogenicity test on both resistant and susceptible rice cultivars showed $B$.oryzae (adapted) as pathogenic on both rice cultivars while $B$. maydis (non-adapted) was non-pathogenic on both rice cultivars. Likewise, pathogenicity test on both resistant and susceptible corn cultivars showed B. maydis (adapted) as pathogenic on both corn cultivars while non-pathogenic on both rice cultivars. According to the study of Tufan (2009) on the pathogenicity profiles of adapted and non-adapted Magnaporthe isolates on wheat cultivars, adapted isolate (BR32 and BR37) were able to cause disease on cv. Renan although lesions formed by these two isolates were encircled by brown necrotic rings, suggesting that Renan is partially resistant to both isolates. On the susceptible cultivar, Thesee, both isolates were fully virulent leading to complete blighting of the leaf. However, BR29 isolate (isolated from the crabgrass species Digitaria sanguinalis) which was previously shown to be unable to infect both rice and barley were confirmed to be non-pathogenic on wheat also.

Susceptible rice cultivar inoculated with $B$. oryzae and susceptible corn cultivar inoculated with $B$. maydis, both adapted pathogen of rice and corn, were observed to produce the highest mean lesion density, lesion size and percentage disease severity among all treatments. A successful pathogen must have conquered this basal immune system and be able to establish colonization on the defeated host (Wen et al. 2011). In addition, susceptible plant has a recessive gene that upon interaction with the dominant or recessive gene of the pathogen will produce the lesions, hence the symptom of the disease (Flor 1946). Following the principle of receptor-elicitor model of gene-forgene interactions, susceptible allele of the plant doesn't encode a receptor that recognizes an elicitor produced by the pathogen (Ruberson \& Tillman 1999). Non-recognition of the pathogen elicitor by the plant receptor leads to plant susceptibility and production of significant lesion size. The same principle holds true to resistance allele of the plants wherein a receptor is present to recognize the elicitor of the pathogen that lead to plant resistance.

Resistant rice cultivar inoculated with $B$. oryzae (adapted pathogen) was not significantly different from the control and B. maydis inoculated leaves across same time points (Table 2). For a well-adapted pathogen, basal resistance is not sufficient to stop the invasive growth and reproduction of the pathogen. Controlled by resistance $(R)$ genes, the host utilizes new branch of immune system often encoding intracellular immune receptors of the nucleotide-binding site and the leucine-rich-repeat (NB-LRR) superfamily to trigger stronger and race-specific resistance (Chisolm et al. 2006, Jones and Dangl 2006). Although, little progress has been made during the past years to identify the key components of non-host disease resistance, plant cellular components can contribute to non-host disease resistance (Mysore and Ryu 2004).

Similar results were also observed when both resistant and susceptible rice and corn varieties were inoculated with non-adapted pathogen. There were no lesions produced similar to the control even after $7 \mathrm{~d}$ of inoculation leading to $0 \%$ disease severity. According to Heath (1991), the concept of gene for gene interaction is not applicable in the case of non-host resistance since the alternative hypothesis of the interaction governs both species and cultivar specificity. It necessitates the assumption that every plant has specific resistance genes for all potential pathogens.

Cytological tests revealed conidia of both Bipolaris species germinated on two hosts but only $B$. maydis produced appressoria on resistant and susceptible corn cultivars. $\mathrm{H}_{2} \mathrm{O}_{2}$ accumualtion around the hyphal tips of susceptible corn cultivar inoculated with the adpated pathogen is due to the turgor pressure exerted by the hyphae which forces the DAB stain to 
acumulate in the immediate surrounding of the swollen hyphae. According to Thordal-Christensen (1997), $\mathrm{H}_{2} \mathrm{O}_{2}$ accumulation can be detected in the epidermal cell wall subjacent to the primary germ tube and appressorium. In addition. in-situ detection of $\mathrm{H}_{2} \mathrm{O}_{2}$ was successfully observed in developing papillae and surrounding haloes (cell-wall appositions) and in the epidermal cells undergoing HR. In the study conducted by Ganesan and Thomas (2001), IR 50 which is a rice cultivar senstive to Magnaporthe grisea showed little DAB staining along the entire length of the vein compared to very deep reddish brown staining in the resistant cultivar inoculated with the same pathogen. The result of the study was not expected since in similar study conducted by Vanacker et al. (2000), there was no evident of browning in the susceptible line of barley inoculated with the adapted pathogen. In contrast, appearance of brown staining, indicative of $\mathrm{H}_{2} \mathrm{O}_{2}$ production is the first sign of events unique to barley- resistant isogenic line (AlgR) cell death response in mesophyll cells underlying some attacked epidermall cells.

In contrast, trypan blue staining which produced death cells, also a form of defense response were formed around the attempted penetration site on resistant rice cultivar inoculated with $B$. maydis at $24 \mathrm{~h}$ after inoculation. HR is one of the common feature of disease resistance which results in the rapid development of cell death immediately surrounding the infection sites (Morel and Dangl 1997). Mansfield et al.(1997) stated that HR is observed in many examples of non-host resistance. Thus, trypan blue staining of resistant rice inoculated with non-adapted pathogen conformed to the expected result.

\section{Acknowledgements}

This work was financed by the Bureau of Agricultural Research (BAR), Philippines for the first author.

\section{References}

Adriano MS. 1989 - Implications for policy of the studies on profitability of irrigated non-rice crop production: A synthesis. Proc. National workshop on Crop Diversification in Irrigated Agriculture in the Philippines. IIMI, Sri Lanka, 134-142.

Anon 2014 -.The Philippine Rice Research Institute (PhilRice). http://www.philrice.gov.ph/ (accessed 13 Feb 2017).

Callahan JR. 2010 - Emerging biological threats: A reference guide. Santa Barbara, Califf, Greenwood Press.

Chakrabarti NK. 2001 - Epidemiology and Disease Management of Brown Spot of Rice in India: In Screenivaprasad, and R. Johnson (eds) Major Fungal Diseases of Rice (Recent Advances). Kluwer Academic Publishers, Netherlands. 293-298.

Chisolm ST, Coaker G, Day B, Staskawicz BJ. 2006 - Host-microbe interactions: shaping the evolution of the plant immune response. Cell12,803-814.

Drechsler C. 1925 - Leaf spot of maize caused by Ophiobolusheterostrophusn.sp. Journal of Agricultural Research 31, 701-726.

Flor HH. 1946 - Genetics of pathogenicity in Melampsora lini. Journal of Agricultural Research 73, 337-357.

Ganesan V,Thomas G. 2001 - Salicylic acid response in rice: influence of salicylic acid on $\mathrm{H}_{2} \mathrm{O}_{2}$ accumulation and oxidative stress. Plant Science.160, 1095-1106.

Heath MC. 1991 - The role of gene-for-gene interactions in the determination of hosts specificity. APS. 81:2

Jones JDG, Dang JL. 2006 - The plant immune system. Nature 444, 323-329.

Keogh RC, Deverall, BJ. Mcleod S. 1980 - Comparison of histological and physiological responses to Phakopsorapachyrhizi in resistant and susceptible soybean. Trans. Br Mycol Soc. 74:329-33.

Kronstad JW. 2000 - Fungal Pathology. Kluwers Academic Publishers, Netherlands. 404 pp. 
Mansfield JW, Bennett MH, Bestwick CS, Woods-Tor AM. 1997. Phenotypic expression of genefor-gene interactions involving fungal and bacterial pathogens: Variation from recognition to response. In: Crute IR, Holub EB, (eds) The Gene-For-Gene Relationships In HostParasite Interactions. CAB International, London, UK. 265 - 291.

Mercado AC, Lantican, RM. 1961 - The susceptibility of cytoplasmic male sterile linesof corn to Helminthosporiummaydis Nish. and Miy. Philippine Agriculturist 45, 235-243.

Morel JB, Dangl JL. 1997 - The hypersensitive response andthe induction of cell death in plants. Cell Death Differentiaiton 4, 671-683.

Mysore KS, Ryu CM. 2004 - Nonhost resistance: how much do we know? Trends in Plant Science 9,97-104.

Ocfemia GO. 1924 - The Helminthosporium disease of rice occurring in the Southern United States and in the Philippines. Am J Bot. 11, 437-460.

Orillo F. 1952 - Leafspot of maize caused by Helminthosporium maydis. Philippine Agriculturist 36, 327-392.

Ou SH. 1985 - Rice Diseases, $2^{\text {nd }}$ ed. Commonwealth Mycological Institute, Kew, UK.

Padmanabhan SY. 1973 - The Great Bengal Famine. Ann. Rev. Phytopathology.11,11-26.

Partridge JE. 1997 - Southern corn leaf blight.

http://jpkc.jluhp.edu.cn/zwkx/zwbl/Improve/Graduate/NebraskaIntroPP/CoSCLB.html.

Romeis T. 2001 - Protein kinases in the plant defense responses. Plant Biology 4,407-414.

Ruberson JR, Tillman PG. 1999 - Effect of selected insecticides on natural enemies in cotton. National Cotton Council of America. Memphis, pp1210-1213.

Sharma PN. 2011 - Measurement of Disease (pdf). Department of Plant Pathology, CSK HPKV, Palampur.

Strange RN. 2003 - Intoduction to Plant Pathology. John Wiley \& Sons Ltd.

Tufan HA. 2009 - Cellular and molecular defense responses of wheat to adapted and non-adapted Magnaporthe species.

Thordal-Christensen H, Zhang Z, Wei Y, Collinge DB. 1997 - Subcellular localization of $\mathrm{H}_{2} \mathrm{O}_{2}$ in plants. $\mathrm{H}_{2} \mathrm{O}_{2}$ accumulation in papillae and hypersensitive response during the barleypowdery mildew interaction. Plant J. 11, 1187-1194.

Tuite J.1969 - Plant Pathological Methods in Fungia and Bacteria:Burgess Publishing Company, Minneapolis Minn.

Vanacker H, Carver TLW, Foyer CH. 2000 - Early $\mathrm{H}_{2} \mathrm{O}_{2}$ accumulation in mesophyll cells leads to induction of glutathione during the hyper-sensitive response in the barley-powdery mildew interaction. Plant Physiology 123, 1289-300.

Wen Y, Wang W, Feng J, Luo MC, Tsuda K, Katagiri F, Bauchan G, Xiao S. 2011 - Identification and utilization of a sow thistle powdery mildew as a poorly adapted pathogen - to dissect post-invasion non-host resistance mechanisms in Arabidopsis. Journal of Experimental Botany 62, 2117-29.

Yu TF. 1933 - Studies on Helminthosporium leaf spot of maize. Sinensia 3, 273-318. 